\title{
Personalized cancer therapy- leveraging a knowledge base for clinical decision-making
}

\author{
Ecaterina lleana Dumbrava ${ }^{1}$ and Funda Meric-Bernstam ${ }^{1,2,3}$ \\ ${ }^{1}$ Department of Investigational Cancer Therapeutics, The University of Texas, MD Anderson Cancer Center, \\ Houston, Texas 77030, USA; ${ }^{2}$ The Sheikh Khalifa Bin Zayed Al Nahyan Institute for Personalized Cancer \\ Therapy, The University of Texas, MD Anderson Cancer Center, Houston, Texas 77030, USA; ${ }^{3}$ Department of \\ Breast Surgical Oncology, The University of Texas, MD Anderson Cancer Center, Houston, Texas 77030, USA
}

\begin{abstract}
Next-generation sequencing (NGS), also known as massively parallel sequencing, is rapidly being incorporated into oncology practice. Interpretation of genomic reports and selecting treatments based on the tumor's genomic analysis becomes more and more complicated for the treating oncologist because of the use of larger panels covering dozens to hundreds of genes and the amount of rapidly emerging clinical/translational data. To help guide personalized treatments in oncology, The Sheikh Khalifa Bin Zayed Al Nahyan Institute for Personalized Cancer Therapy (IPCT) at MD Anderson Cancer Center has developed a knowledge base, available at https://personalizedcancertherapy.org or https://pct. mdanderson.org (PCT). This knowledge base provides information on the function of common genomic alterations and their therapeutic implications. Here, we describe how such genomic information can be used by health-care providers to identify genomically matched therapies.
\end{abstract}

Corresponding author: fmeric@mdanderson.org

(C) 2018 Dumbrava and MericBernstam This article is distributed under the terms of the Creative Commons Attribution-NonCommercial License, which permits reuse and redistribution, except for commercial purposes, provided that the original author and source are credited.

Published by Cold Spring Harbor Laboratory Press

doi: $10.1101 /$ mcs.a001578

\section{INTRODUCTION}

Selecting the right treatment for patients with cancer is a complex decision based on continuously evolving molecular diagnostics and rapidly emerging biomedical literature. Tracking associations between actionable genomic alterations and targeted therapies in clinical trials can be challenging for treating oncologists and researchers alike. Chemotherapy has remained the backbone of cancer treatment for many tumor types, but has limited response rates and notable side effects. The driver molecular mechanisms involved in cancer initiation, progression, and resistance are increasingly pursued as therapeutic targets. Examples of successful personalized cancer treatments have revolutionized oncology, such as targeting HER2 in breast cancer (Slamon et al. 2001; Wolff et al. 2013), bcr-abl in chronic myeloid leukemia (Druker et al. 2006), or ALK in non-small-cell lung cancer (NSCLC) (Shaw et al. 2013, 2014; Holla et al. 2017).

Precision medicine in oncology spans a continuum, ranging from efforts to identify diagnostic biomarkers (to detect the occurrence of cancer in healthy patients, to identify tumors earlier), prognostic biomarkers (to predict the natural course of the disease), predictive biomarkers (to predict the clinical outcome in the presence of a specific therapy), and pharmacogenomic biomarkers (to identify alterations in drug metabolism and predict response and toxicities related to a specific treatment). 
There is an urgent need to identify new biomarkers that can predict sensitivity or resistance to targeted therapies and immunotherapy. Although these treatments have revolutionized cancer treatment in the last decade, only a limited number of patients respond to these treatments. If a tumor has a known driver genomic alteration and there is a FDA-approved drug for that alteration in that particular tumor type (e.g., EML4-ALK fusion in NSCLC and crizotinib or BRAF p.V600E mutation in melanoma and vemurafenib) (Chapman et al. 2011; Shaw et al. 2013), the treatment choice is relatively straightforward. Unfortunately, at this time there are only a handful of genomic predictive biomarkers linked to FDA-approved drugs in selected diseases.

Using biomarkers, oncologists can identify which patients can benefit or not from these drugs before starting the treatment, avoiding unnecessary toxicity (Bailey et al. 2014).

In this commentary, we describe the Personalized Cancer Therapy knowledge base that is available at https://pct.mdanderson.org (PCT) and how it can be used to support clinical decision-making. PCT allows users to access information about the clinical significance and actionability of genomic alterations and to identify matched targeted therapies, leading to better outcomes for patients (Von Hoff et al. 2010; Tsimberidou et al. 2012; Fontes et al. 2015; Schwaederle 2015; Massard et al. 2017).

\section{GENOMIC PROFILING OF TUMORS AND ITS CHALLENGES FOR ONCOLOGISTS}

Molecular profiling can be defined as the testing of DNA, mRNA, protein abnormalities, or epigenetic changes and is essential for identification of predictive biomarkers associated with a cancer's phenotype, prognosis, and clinical outcome.

The most widely used molecular profiling approach is DNA next-generation sequencing (NGS), which has increased in availability and usefulness in response to publicly accessible databases sharing information about clinically actionable variants and increasing number of therapeutic opportunities. Other molecular methods such as transcriptome profiling for mRNA expression, reverse phase protein array (RPPA) for functional proteomics abnormalities, or methylome profiling for epigenetic changes are emerging; however, their clinical utility is still to be confirmed.

Integrating molecular profiling in patient care starts with identifying the tumor sample on which the analysis will be conducted. To overcome cancer heterogeneity, testing of circulating cell-free tumoral DNA (cfDNA) could be considered (Fig. 1, Step 1; Jovelet et al. 2016; Shaw et al. 2016).

NGS is an effective way to capture a large amount of genomic information. In oncology, a variety of approaches for NGS are being explored including NGS targeted panels, in which sequencing is performed for genome fragments for known hotspots where frequently pathogenic mutations occur, or whole-exome NGS, in which all the coding exons of all genes are sequenced (Fig. 1, Step 2).

\section{"... determining the actionable genomic alterations in a patient's tumor and targeted therapies that are available for that alteration can be challenging for treating oncologists and researchers alike."}

The development of NGS technologies has led to an increased number of genes sequenced and much more information, which is not all clinically relevant. After NGS of a tumor sample, a clinical report is generated with the significant identified variants, which must be annotated according to the Human Genome Variation Society (HGVS) guidelines (Fig. 1, Step 3; Richards et al. 2015). 

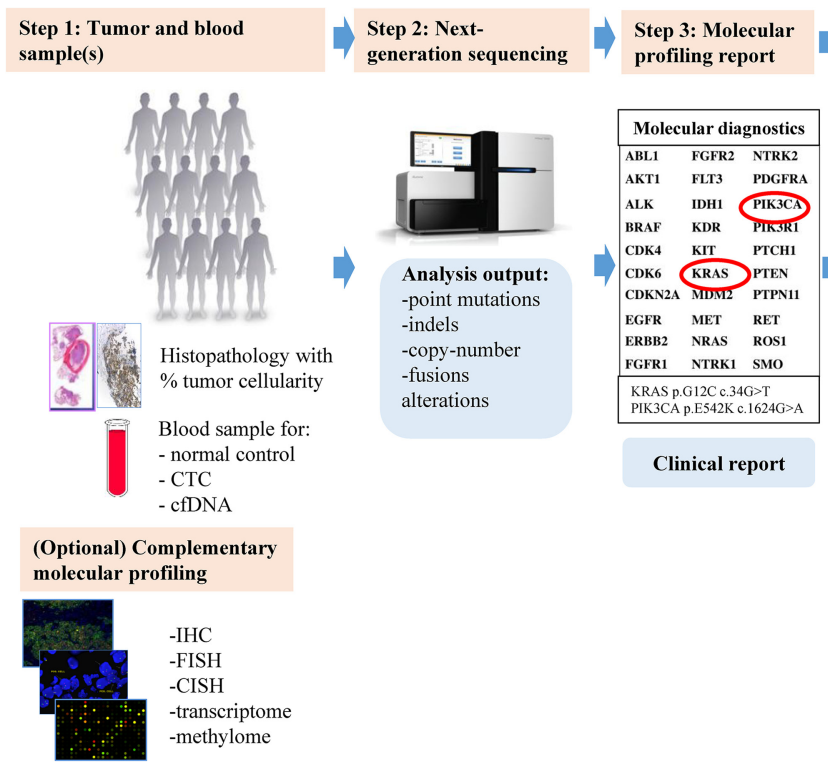

Step 4: Clinical significance annotation of genomic alterations and their use in clinical practice

MDAnderson Personalized Cancer Therapy GancerCenter https://pct.mdanderson.org

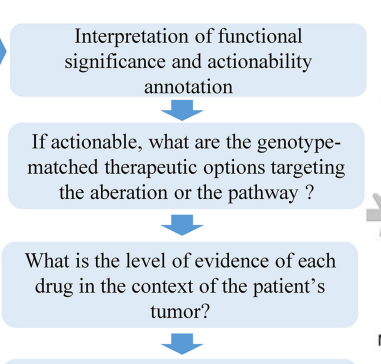

Are the agents FDA approved or available through a clinical trial ?

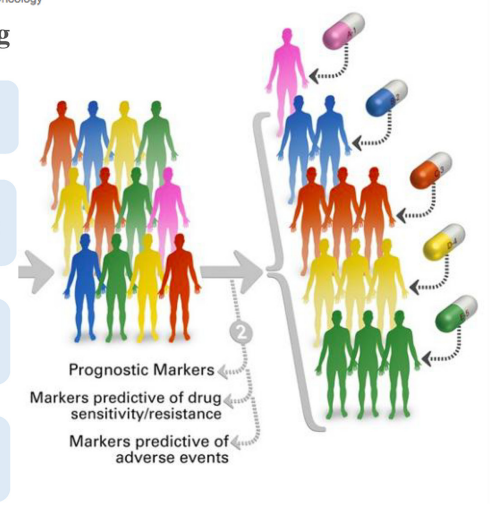

Figure 1. Precision oncology decision support (PODS) for personalized cancer therapy: from molecular alteration detection to identification of genomically based appropriate treatment. (Adapted with permission from https://pct.mdanderson.org.)

Understanding the molecular testing process is important for the interpretation of the results and determining the best personalized treatment option for the patient (Fig. 1, Step 4). This step, in determining the actionable genomic alterations in a patient's tumor and targeted therapies that are available for that alteration can be challenging for treating oncologists and researchers alike (Roychowdhury and Chinnaiyan 2013; André et al. 2014).

Variant analysis and interpretation must be performed by an expert to evaluate the validity and clinical utility of each variant (Heuckmann and Thomas 2015). For the information to be used in clinical decision-making, the functional and clinical significance of the variants must be assessed.

In the absence of the decision support for oncologists as described above, optimal treatment of patients may not be offered. Genotype-matched treatment in the setting of a known pathogenic actionable genomic alteration can be overlooked, or patients may be offered offlabel therapy targeting nonactionable variants (Krzyzanowska et al. 2013). Matching of patients with alterations in actionable genes that are not actionable variants or treating patients with therapies that do not truly target the alteration or that are not best in class may also adversely affect clinical trial results (Le Tourneau et al. 2015).

Recent studies to evaluate the clinical impact of precision oncology have detected improved survival endpoints and, in some cases, a neutral economic impact (Schwaederle et al. 2016; Haslem et al. 2017; Massard et al. 2017). A large meta-analysis of more than 8000 patients with refractory cancer who received genomics-targeted therapy identified a near-doubling of progression-free survival and prolonged overall survival, compared with patients who received nontargeted therapy (Schwaederle et al. 2015).

\section{PERSONALIZED CANCER THERAPY—KNOWLEDGE BASE FOR PRECISION ONCOLOGY}

The Sheikh Khalifa Bin Zayed Al Nahyan Institute for Personalized Cancer Therapy (IPCT) at the University of Texas MD Anderson Cancer Center has developed a knowledge 
base to support preclinical research and clinical trials by assessing the clinical significance and actionability of genomic alterations and identification of matched targeted therapies. This is available to the public through the Personalized Cancer Therapy website (https://personalizedcancertherapy.org or https://pct.mdanderson.org (PCT) (Kurnit et al. 2017). This multidimensional data source aims to support both clinicians and researchers in the effort of implementing personalized cancer therapy by providing information about the actionability of genes and functional significance of variants.

The information presented on this website is not intended to provide direct treatment recommendations but rather to synthesize what is known about cancer-related genes and their implications for cancer treatment. The knowledge base currently is focused on DNAbased alterations and includes many of the recurrently altered genes, each with information on specific alterations and their therapeutic implications.

The website is organized in a gene-focused manner, regardless of tumor type. The information on the website is presented in a user-friendly manner to be easily accessible, interpreted, and utilized by physicians and patients. Users can search not only by gene but also by specific variants. Functional implications are included for many of the variants whose functional impact has literature support. For these alterations, matched available clinical trials can be found through the PCT website. In a recent review, Holla et al. (2017) discussed ALK alterations and their therapeutic implifications, illustrating how the information available on alterations within a gene, their actionability, and functional significance can be useful in linking a target with a matched treatment. On the PCT website there is detailed information available for 32 actionable genes for which the data were curated, and the information regarding alterations and clinical trials is updated weekly.

Key features of the website for each gene are as follows.

1. Overview: General information on the gene and its functions with a figure of the signaling pathway in which the mutated gene product is implicated and relationship with other mediators in the signaling cascade.

2. Alterations: Review of alterations in that gene with visualization of mutations and germline variations, copy-number variations, and fusion descriptions with their frequency in different tumor types.

3. Frequencies and outcomes: Somatic alteration frequencies in different tumor types and germline variants causing cancer.

4. Therapeutic implications: Description of therapeutic implications of the alterations with level of evidence of drug effectiveness in a specific tumor type harboring a specific biomarker.

5. Drugs: Food and Drug Administration (FDA)-approved drugs or investigational therapeutics in clinical trials targeting a pathway.

6. Clinical trials: Information on the genotype-selected clinical trials and genotype-relevant clinical trials.

In addition to high-throughput literature retrieval from the MEDLINE database, the literature is manually reviewed by a PODS (Precision Oncology Decision Support) team that includes oncologists, geneticists, molecular biologists, computational scientists, computer programmers, and bioinformaticians. They validate and record the functional implication in tumorigenesis of each alteration and determine whether the alteration is a predictive biomarker for sensitivity or resistance to a specific drug, or whether it is involved in cancer prognosis, with critical input from gene and disease experts (Johnson et al. 2015). A detailed description of how the content on PCT is generated and maintained has recently been published (Kurnit et al. 2017). 
The National Cancer Institute (NCl) description of the drug, drug aliases, FDA-approved indications, and the clinical trial development statuses are included in the available information on the website. This information is retrieved from the $\mathrm{NCl}$ Drug Dictionary, other databases such as Selleckchem.com, MedKoo.com, DGldb: Mining the Druggable Genome, and scientific literature, which are all used to compile a list of drugs that either target the mutated gene product or target downstream mediators of the mutated signaling pathways (Xu et al. 2016).

There are other online resources for precision oncology decision support as presented in Table 1. This is not a comprehensive list, but rather these are some of the most frequently used online precision oncology resources. These knowledge bases often differ in how data was curated, the number of genes curated, and how the information is organized. These online tools are complementary in helping researchers and physicians in advancing cancer research and decisions about treatment options by providing information on genomic alterations and matched drugs.

To accelerate personalized cancer therapy there are ongoing efforts to create a shared knowledge base across multiple institutions worldwide (The AACR Project GENIE). The GENIE database is expected to grow to more than 100,000 samples within 5 years and will be a powerful tool for identification of novel therapeutic targets, design of biomarkerdriven clinical trials, and identification of genomic determinants of response to therapy (AACR Project GENIE Consortium 2017).

Some of the strengths of PCT are the straightforward search based on gene or variant, the easy readability of the information structured from overview of the gene, and the pathway to clinical implications and clinical trials search. The data are curated by the PODS scientists with expertise in molecular biology, genetics, computational science, and bioinformatics. Their expertise and their collaboration with world-renowned physicians and researchers at MD Anderson, as well as the extended MD Anderson Cancer Center experience with genomically targeted therapies, make PCT one of the strongest tools in precision oncology. A potential limitation of the site is the fact that it is not organized by tumor type but rather gene. However,

\begin{tabular}{|c|c|c|c|}
\hline Name & Website & Supported by & Publication(s) \\
\hline $\begin{array}{l}\text { Personalized } \\
\text { Cancer } \\
\text { Therapy }\end{array}$ & $\begin{array}{l}\text { www.personalizedcancertherapy. } \\
\text { org }\end{array}$ & $\begin{array}{l}\text { The University of Texas } \\
\text { MD Anderson Cancer } \\
\text { Center }\end{array}$ & Kurnit et al. 2017 \\
\hline $\begin{array}{l}\text { My Cancer } \\
\text { Genome }\end{array}$ & www.mycancergenome.org & $\begin{array}{l}\text { Vanderbilt-Ingham } \\
\text { Medical Center }\end{array}$ & Van Allen et al. 2013 \\
\hline OncokB & oncokb.org & $\begin{array}{l}\text { Memorial Sloan } \\
\text { Kettering Cancer } \\
\text { Center, partnership } \\
\text { with Quest } \\
\text { Diagnostics }\end{array}$ & Zehir et al. 2017 \\
\hline $\begin{array}{l}\text { Drug Gene } \\
\text { Interaction } \\
\text { Database }\end{array}$ & www.dgidb.genome.wustl.edu & $\begin{array}{l}\text { Washington University } \\
\text { in St. Louis }\end{array}$ & $\begin{array}{l}\text { Wagner et al. 2016; } \\
\text { Griffith et al. } 2017\end{array}$ \\
\hline CIViC & www.civic.genome.wustl.edu & & \\
\hline JAX CKB & www.ckb.jax.org & Jackson Laboratory & Patterson et al. 2016 \\
\hline PMKB & www.pmkb.weill.cornell.edu & Cornell University & Huang et al. 2017 \\
\hline $\begin{array}{l}\text { Precision Cancer } \\
\text { Medicine }\end{array}$ & www.precisioncancermedicine.org & $\begin{array}{l}\text { Dana Farber/Brigham } \\
\text { and Women's Cancer } \\
\text { Center }\end{array}$ & Not applicable \\
\hline
\end{tabular}


tumor-specific information is listed within the gene page, and the gene-centric approach makes it more user-friendly when seeking histology-agnostic therapies, as one would when a rare alteration is found in a common tumor type or while treating a patient with a rare tumor type. Also, an application program interface (API) is not available at this time.

\section{INTERPRETING THE FUNCTIONAL SIGNIFICANCE AND ACTIONABILITY OF A GENOMIC ALTERATION}

Most of the scientific evidence of drug response is associated with collective mutations within a gene rather than with specific alterations of that gene. However, an oncologist needs to determine whether a specific mutation in a patient's tumor is likely to affect the function of a gene and its therapeutic implications. Based on the site of a gene mutation and a change in the amino acid sequence, a mutation can lead to a change in the activity, expression, or stability of the expressed protein. And in the same gene one can find mutations that confer sensitivity to treatment and others that will result in resistance (e.g., EGFR deletions in the exon 19 predict sensibility to EGFR inhibitors and EGFR T790M mutation for resistance to EGFR inhibitors).

Oncologists have several important tasks to complete after receiving the molecular profile report from a Clinical Laboratory Improvement Amendments (CLIA)-certified laboratory in order to be able to offer genomically informed care. First, they need to determine what tissue was tested and the reliability of the test report. Then, they need to determine whether there are alterations in actionable genes and, if so, how the alterations may affect the function of these genes. If there are actionable alterations, one needs to determine the therapeutic implications and available approved or investigational agents targeting that alteration. Ultimately, one needs to weigh the level of evidence that a biomarker would confer sensitivity to a drug, in the context of a specific disease, and compare the likelihood of efficacy of genotype-selected options with that of alternate approved or investigational therapies. These several steps need to be completed in the limited time allotted for clinical encounters or while preparing for a clinical encounter in advance. Through the PCT website, the PODS team facilitates the clinical oncologists' task by annotating the gene's and gene alteration's actionability and functional significance and by listing available genomically matched clinical trials. PCT was created to be a useful reference and to provide information on functional implications of recurrent mutations in cancer related genes. The variants listed are limited to those that have been characterized and published in the scientific literature. This is supplemented by medical graphics that allow a user to determine the location of a given variant within the context of the functional domains of a gene. More details about the alteration and the curation process that was used in determining the actionability and functional significance of the alteration can be requested via email (emailpct@mdanderson.org).

\section{AVAILABILITY OF RELEVANT FDA-APPROVED THERAPIES OR INVESTIGATIONAL AGENTS IN CLINICAL TRIALS}

If a tumor has a known genomic alteration and there is a FDA-approved drug for that alteration in that tumor type (e.g., EML4-ALK fusion in NSCLC [Holla et al. 2017] or BRAF p.V600E mutation in melanoma) (Chapman et al. 2011), the treatment choice is relatively straightforward. Unfortunately, there are only a few molecular targets with matched FDA-approved drugs (Meric-Bernstam et al. 2015). For the rest of the actionable alterations, oncologists could consider enrollment of the patient in a genotype-relevant clinical trial. This process of clinical trial finding can be very time-consuming for oncologists, because for most clinical trials the molecular subsets that they are targeting have not been made publically available. 
To facilitate the choice of genomically informed treatment, the PCT website provides, in the "Clinically Available Drugs" section of each gene page, the clinical trials available for that specific alteration.

Finally, PCT serves as a resource for genotype-matched trials. The clinical trials can be classified as "genotype-selected," in which as eligibility criteria trials require to have a specific genomic alteration, or "genotype-relevant," in which there are no requirements for a specific genomic alteration, but there are preferred biomarkers for drugs that target a specific gene product or downstream signaling relevant to the molecular alteration.

Off-label use of targeted therapies is often considered because of lack of access to clinical trials; however, to evaluate efficacy of agents and to generate the data for approval of genomically matched therapies, patients should be enrolled in genotype-based clinical trials whenever possible. Access to targeted agents is increased through initiatives such as $\mathrm{NCl}$ MATCH (NCT024665060) and TAPUR (NCT02693525).

\section{FINAL REMARKS}

Genomic testing is increasingly being utilized for clinical decision-making. PCT is an openaccess website serving as a knowledge base for precision oncology. The website is expanding and continuously updating with new information as the data behind the portal are being curated by scientists and clinicians with domain expertise. This information can help determine the functional impact of specific alterations and help facilitate and identify optimal genomically driven approved or investigational options. The website provides automatic updates on clinical trials utilizing genomically matched therapies and can help guide patient enrollment to biomarker-driven clinical trials in the absence of a FDA-approved indication and can expedite drug development.

Although the knowledge base is currently based on DNA sequencing, integration of RNA and protein analysis may provide additional information on tumor biology and further treatment options in the future. Furthermore, with integration of immunotherapies in the standard treatment of different cancer types, information on the tumor microenvironment and immune system need to be incorporated into personalized therapy as predictive biomarkers of response are developed. We hope that ultimately enhanced accrual on precision oncology trials will further demonstrate the utility of genomic testing and expedite approval of effective genomically matched therapies.

\section{ADDITIONAL INFORMATION}

\section{Acknowledgments}

We acknowledge the people who have contributed to the development of the database, including The Sheikh Khalifa Bin Zayed Al Nahyan Institute of Personalized Cancer Therapy (IPCT) and Precision Oncology Decision Support (PODS) management: John Mendelsohn, MD; Gordon Mills, MD, PhD; Kenna Shaw, PhD; and Funda Meric-Bernstam, MD.

PODS Scientists Team: Ann Bailey, PhD; Amber Johnson, PhD; Nora Sánchez, PhD; Vijaykumar Holla, PhD; Yekaterina Khotskaya, PhD; Jia Zeng, PhD; Md Abu Shufean, MS; Dong Yang, PhD; and Michael Kahle, PhD.

PODS Informatics Collaborators: Jia Zeng, PhD; Ken Chen, PhD; Hao Zhao, PhD; Xiaofeng Zheng, PhD; Bradley Broom, PhD; Keith Baggerly, PhD; Elmer Bernstam, MD, MSE; Trevor Cohen, PhD, MBChB; Hua Xu, PhD; and W. Jim Zheng, PhD.

Oncology Collaborators: Naoto Tada Ueno, MD, PhD; John Heymach, MD, PhD; Lauren Averett Byers, MD; Scott Woodman, MD, PhD; Scott Kopetz, MD, PhD; Cathy Eng, MD; 
Competing Interest Statement

The authors have declared no competing interest.
Michael Overman, MD; Michael Davies, MD, PhD; Gerald Falchook, MD; David Hong, MD; Vivek Subbiah, MD; Filip Janku, MD, PhD; Anthony Conley, MD; Faye Johnson, MD; Vinod Ravi, MD; Sarina Piha-Paul, MD; Keyur P. Patel, MD, PhD; Marina Konapleva, MD, PhD; Nitin Jain, MD; Guatam Borthakur, MD; Neeta Somaiah, MD; Kathryn Gold, MD; Bonnie Glisson, MD; Sharon Giordano, MD, MPH; Lee Ellis, MD; Gilbert Cote, PhD; and Naifa Lamki Busaidy, MD, FACP, FACE.

\section{Funding}

The Personalized Cancer Therapy Knowledge Base for Precision Oncology (PCT) website (https://pct.mdanderson.org) is supported through funds given generously to the Sheikh Khalifa al Nahyan Ben Zayed Institute of Personalized Cancer Therapy by The Bosarge Family Foundation and the Cancer Prevention Research Institute of Texas. Other support was received from the National Center for Advancing Translational Sciences (NCATS) grant UL1 TR000371, 1U01 CA180964, the MD Anderson Cancer Center Support grant P30 CA016672, and the MD Anderson Cancer Center.

\section{REFERENCES}

AACR Project GENIE Consortium. 2017. ACR Project GENIE: powering precision medicine through an international consortium. Cancer Discov 7: 1-14.

André F, Mardis E, Salm M, Soria JC, Siu LL, Swanton C. 2014. Prioritizing targets for precision cancer medicine. Ann Oncol 25: 2295-2303.

Bailey A, Mao Y, Zeng J, Holla V, Johnson A, Brusco L, Chen K, Mendelsohn J, Routbort MJ, Mills GB, et al. 2014. Implementation of biomarker-driven cancer therapy: existing tools and remaining gaps. Discov Med 17: 101-111.

Chapman PB, Hauschild A, Robert C, Haanen JB, Ascierto P, Larkin J, Dummer R, Garbe C, Testori A, Maio M, et al. 2011. Improved survival with vemurafenib in melanoma with BRAF V600E mutation. N Engl J Med 364: $2507-2516$

Druker BJ, Guilhot F, O'Brien SG, Gathmann I, Kantarjian H, Gattermann N, Deininger MWN, Silver RT, Goldman JM, Stone RM, et al. 2006. Five-year follow-up of patients receiving imatinib for chronic myeloid leukemia. N Engl J Med 355: 2408-2417.

Fontes Jardim DL, Schwaederle M, Wei C, Lee JJ, Hong DS, Eggermont AM, Schilsky RL, Mendelsohn J, Lazar V, Kurzrock R. 2015. Impact of a biomarker-based strategy on oncology drug development: a meta-analysis of clinical trials leading to FDA approval. J Natl Cancer Inst 107: djv253.

Griffith M, Spies NC, Krysiak K, McMichael JF, Coffman AC, Danos AM, Ainscough BJ, Ramirez CA, Rieke DT, Kujan L, et al. 2017. CIViC is a community knowledgebase for expert crowdsourcing the clinical interpretation of variants in cancer. Nat Genet 49: 170-174.

Haslem DS, Van Norman SB, Fulde G, Knighton AJ, Belnap T, Butler AM, Rhagunath S, Newman D, Gilbert H, Tudor BP, et al. 2017. A retrospective analysis of precision medicine outcomes in patients with advanced cancer reveals improved progression-free survival without increased health care costs. J Oncol Pract 13: e108-e119.

Heuckmann JM, Thomas RK. 2015. A new generation of cancer genome diagnostics for routine clinical use: overcoming the roadblocks to personalized cancer medicine. Ann Oncol 26: 1830-1837.

Holla VR, Elamin YY, Bailey AM, Johnson AM, Litzenburger BC, Khotskaya YB, Sanchez NS, Zeng J, Shufean MA, Shaw KR, et al. 2017. ALK: a tyrosine kinase target for cancer therapy. Cold Spring Harb Mol Case Stud 3: a001115.

Huang L, Fernandes H, Zia H, Tavassoli P, Rennert H, Pisapia D, Imielinski M, Sboner A, Rubin MA, Kluk M, et al. 2017. The cancer precision medicine knowledge base for structured clinical-grade mutations and interpretations. J Am Med Inform Assoc 24: 513-519.

Johnson A, Zeng J, Bailey AM, Holla V, Litzenburger B, Lara-Guerra H, Mills GB, Mendelsohn J, Shaw KR, Meric-Bernstam F. 2015. The right drugs at the right time for the right patient: the MD Anderson precision oncology decision support platform. Drug Discov Today 20: 1433-1438.

Jovelet C, lleana E, Le Deley MC, Motte N, Rosellini S, Romero A, Lefebvre C, Pedrero M, Pata-Merci N, Droin N, et al. 2016. Circulating cell-free tumor DNA analysis of 50 genes by next-generation sequencing in the prospective MOSCATO trial. Clin Cancer Res 22: 2960-2968. 
Krzyzanowska MK. 2013. Off-label use of cancer drugs: a benchmark is established. J Clin Oncol 31: 1125-1127.

Kurnit K, Bailey AM, Zeng J, Johnson AM, Shufean MA, Brusco L, Litzenburger BC, Sánchez NS, Khotskaya YB, Holla V, et al. 2017. "Personalized Cancer Therapy": a publicly available precision oncology resource. Cancer Research 77: e123-e126.

Le Tourneau C, Delord JP, Gonçalves A, Gavoille C, Dubot C, Isambert N, Campone M, Trédan O, Massiani MA, Mauborgne $C$, et al. 2015. Molecularly targeted therapy based on tumour molecular profiling versus conventional therapy for advanced cancer (SHIVA): a multicentre, open-label, proof-of-concept, randomised, controlled phase 2 trial. Lancet Oncol 16: 1324-1334.

Massard C, Michiels S, Ferté C, Le Deley MC, Lacroix L, Hollebecque A, Verlingue L, Ileana E, Rosellini S, Ammari S, et al. 2017. High-throughput genomics and clinical outcome in hard-to-treat advanced cancers: results of the MOSCATO 01 trial. Cancer Discov 7: 586-595.

Meric-Bernstam F, Johnson A, Holla V, Bailey AM, Brusco L, Chen K, Routbort M, Patel KP, Zeng J, Kopetz S, et al. 2015. A decision support framework for genomically informed investigational cancer therapy. J Natl Cancer Inst 11: pii: djv098.

Patterson S, Liu R, Statz CM, Durkin D, Lakshminarayana A, Mockus SM. 2016. The clinical trial landscape in oncology and connectivity of somatic mutational profiles to targeted therapies. Human Genomics 10: 4.

Richards S, Aziz N, Bale S, Bick D, Das S, Gastier-Foster J, Grody WW, Hegde M, Lyon E, Spector E, et al. 2015. Standards and guidelines for the interpretation of sequence variants: a joint consensus recommendation of the American College of Medical Genetics and Genomics and the Association for Molecular Pathology. Genet Med 17: 405-424.

Roychowdhury S, Chinnaiyan AM. 2013. Advancing precision medicine for prostate cancer through genomics. J Clin Oncol 31: 1866-1873.

Schwaederle M, Zhao M, Lee JJ, Eggermont AM, Schilsky RL, Mendelsohn J, Lazar V, Kurzrock R. 2015. Impact of precision medicine in diverse cancers: a meta-analysis of phase II clinical trials. J Clin Oncol 33: 3817-3825.

Schwaederle M, Zhao M, Lee JJ, Lazar V, Leyland-Jones B, Schilsky RL, Mendelsohn J, Kurzrock R. 2016. Association of biomarker-based treatment strategies with response rates and progression-free survival in refractory malignant neoplasms: a meta-analysis. JAMA Oncol 11: 1452-1459.

Shaw AT, Kim DW, Nakagawa K, Seto T, Crinó L, Ahn M-J, De Pas T, Besse B, Solomon BJ, Blackhall F, et al. 2013. Crizotinib versus chemotherapy in advanced ALK-positive lung cancer. N Engl J Med 368: 2385-2394.

Shaw AT, Kim DW, Mehra R, Tan DSW, Felip E, Chow LQM, Camidge DR, Vansteenkiste J, Sharma S, De Pas T, et al. 2014. Ceritinib in ALK-rearranged non-small-cell lung cancer. N Engl J Med 370: 1189-1197.

Shaw AJ, Guttery DS, Hills A, Fernandez-Garcia D, Page K, Rosales B, Goddard KS, Hastings RK, Luo J, Ogle O, et al. 2016. Mutation analysis of cell-free DNA and single circulating tumor cells in metastatic breast cancer patients with high CTC counts. Clin Cancer Res 6: 1-9.

Slamon DJ, Leyland-Jones B, Shak S, Fuchs H, Paton V, Bajamonde A, Fleming T, Eiermann W, Wolter J, Pegram M, et al. 2001. Use of chemotherapy plus a monoclonal antibody against HER2 for metastatic breast cancer that overexpresses HER2. N Engl J Med 344: 783-792.

Tsimberidou AM, Iskander NG, Hong DS, Wheler JJ, Falchook GS, Fu S, Piha-Paul S, Naing A, Janku F, Luthra R, et al. 2012. Personalized medicine in a phase I clinical trials program: the MD Anderson Cancer Center initiative. Clin Cancer Res 18: 6373-6383.

Van Allen EM, Wagle N, Levy MA. 2013. Clinical analysis and interpretation of cancer genome data. J Clin Oncol 31: 1825-1833.

Von Hoff DD, Stephenson JJ Jr, Rosen P, Loesch DM, Borad MJ, Anthony S, Jameson G, Brown S, Cantafio N, Richards DA, et al. 2010. Pilot study using molecular profiling of patients' tumors to find potential targets and select treatments for their refractory cancers. J Clin Oncol 28: 4877-4883.

Wagner AH, Coffman AC, Ainscough BJ, Spies NC, Skidmore ZL, Campbell KM, Krysiak K, Pan D, McMichael JF, Eldred JM, et al. 2016. DGldb 2.0: mining clinically relevant drug-gene interactions. Nucleic Acids Res 44: D1036-D1044.

Wolff AC, Hammond ME, Hicks DG, Dowsett M, McShane LM, Allison KH, Allred DC, Bartlett JM, Bilous M, Fitzgibbons $P$, et al. 2013. Recommendations for human epidermal growth factor receptor 2 testing in breast cancer: American Society of Clinical Oncology/College of American Pathologists clinical practice guideline update. J Clin Oncol 31: 3997-4013.

Xu J, Lee HJ, Zeng J, Wu Y, Zhang Y, Huang LC, Johnson A, Holla V, Bailey AM, Cohen T, et al. 2016. Extracting genetic alteration information for personalized cancer therapy from ClinicalTrials.gov. J Am Med Inform Assoc 23: 750-757.

Zehir A, Benayed R, Shah RH, Syed A, Middha S, Kim HR, Srinivasan P, Gao J, Chakravarty D, Devlin SM, et al. 2017. Mutational landscape of metastatic cancer revealed from prospective clinical sequencing of 10,000 patients. Nat Med 23: 703-713. 


\section{COLD SPRING HARBOR Molecular Case Studies}

\section{Personalized cancer therapy_-leveraging a knowledge base for clinical decision-making}

Ecaterina lleana Dumbrava and Funda Meric-Bernstam

Cold Spring Harb Mol Case Stud 2018, 4: a001578 originally published online December 6, 2017 Access the most recent version at doi: $10.1101 /$ mcs.a001578

References This article cites 34 articles, 12 of which can be accessed free at: http://molecularcasestudies.cshlp.org/content/4/2/a001578.full.html\#ref-list-1

License This article is distributed under the terms of the Creative Commons Attribution-NonCommercial License, which permits reuse and redistribution, except for commercial purposes, provided that the original author and source are credited.

Email Alerting Receive free email alerts when new articles cite this article - sign up in the box at the Service top right corner of the article or click here. 